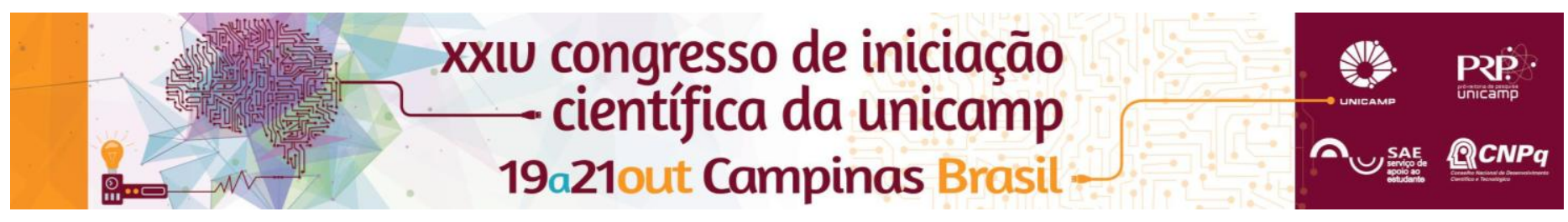

\title{
ESTRESSE PERCEBIDO EM ESTUDANTES DE CIÊNCIAS BIOLÓGICAS: DADOS
} PRELIMINARES.

\section{Fernanda S. Facchini ${ }^{\star}$, Fernando Canova}

\section{Resumo}

Estresse pode ser definido como a reação do organismo que ocorre quando há uma adaptação a um evento ou situação. Temos o objetivo de utilizar a escala de estresse percebido em alunos de Ciências Biológicas da UMC. Não encontramos diferenças significativas entre homens e mulheres, no entanto, por se tratar de dados preliminares, acreditamos que poderemos observar variações entre homens e mulheres, turma e período de aulas, e dessa forma promover melhor qualidade de vida e de seus estudos.

\section{Palavras-chave:}

Estresse, cronotipo, resiliência

\section{Introdução}

Estresse é a forma física e mental em que devemos reagir a situações de perigo, alerta ou pressão, essa reação pode causar sintomas mentais e físicos e os efeitos variam de pessoa para pessoa. Estresse, ansiedade, esgotamento são termos usados com grande frequência na vida moderna, devido a grande exposição da sociedade a competitividade e segurança sociais, competência profissional, a sobrevivência econômica, perspectivas futuras e mais uma infinidade de ameaças abstratas e reais. Assim, temos como objetivos estudar o nível de estresse em estudantes de ciências biológicas, e então contribuir para entender as alterações que por ventura se manifestar em decorrência dos desequilíbrios causados no organismo pela situação de estresse.

Para estas análises optamos pela utilização da Escala de Estresse Percebido (Perceived Stress Scale (PSS) de Cohen, Karmack, \& Mermelsteinm, 1983) é o instrumento mais utilizado para avaliar a percepção do estresse, tendo sido validada em mais de 20 países.

A PSS avalia a percepção do indivíduo sobre os quão imprevisíveis e incontroláveis the parecem os eventos de vida experienciados no último mês.

\section{Resultados e Discussão}

Estão previstos para este projeto a participação de 181 alunos regularmente matriculados no curso de Ciências Biológicas da Universidade de Mogi das Cruzes - UMC, serão aplicados a PSS e o questionário de Cronotipo. Desta forma pretendemos associar o cronotipo dos voluntários aos índices de estresse percebido. Além das variações que poderão ser encontradas em relação aos períodos Diurno ou Noturno.

Todos os procedimentos foram aprovados pelo Comitê de ética em Pesquisas (CEP) via Plataforma Brasil do Ministério da Saúde sob número: 54732116.6.0000.5497. A média e DP de estresse percebido somando-se todos os sujeitos foi de $29,8 \pm 6,0$, sendo que entre mulheres foi encontrado $34,0 \pm 2,6$ e para homens foi encontrado $25,6 \pm 5,6$. As análises estatísticas utilizando-se o teste $T$ não encontrou diferenças significativas entre homens e mulheres $\mathrm{p}<0,05$ (Figura 1). Por se tratar de um estudo com dados preliminares, algumas das análises ainda serão feitas.

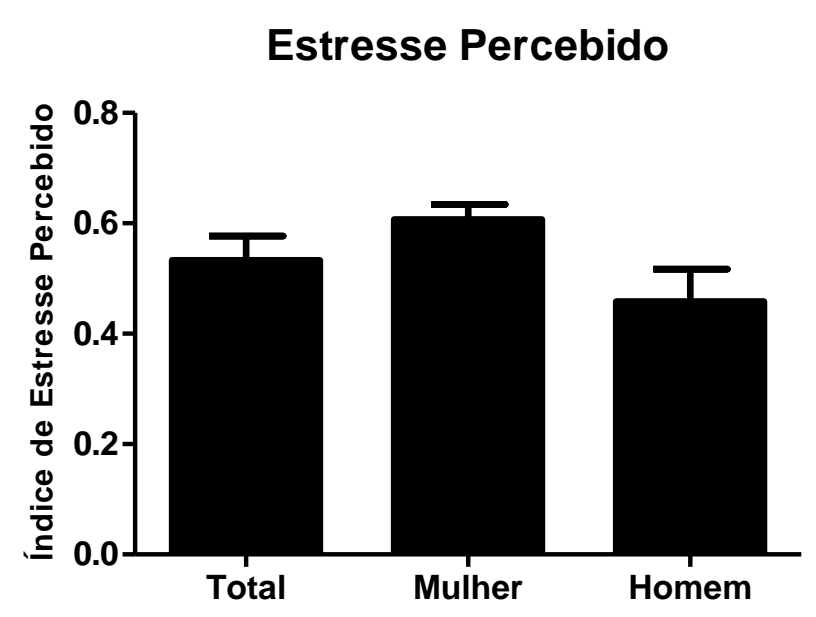

\section{Conclusões}

Não foram encontradas diferenças significativas entre os grupos, no entanto, acreditamos que este fato esteja relacionado ao baixo número de participantes analisados até o momento $(n=6)$. Após a finalização deste projeto teremos dados suficientes para relacionar os valores encontrados na PSS dos voluntários aos cronotipos e ainda possíveis variações relacionadas ao período e a turma dos voluntários.

\section{Agradecimentos}

Os pesquisadores agradecem a todos os participantes voluntários desta pesquisa, aos professores que gentilmente cederam espaço de suas aulas para explicações do projeto aos alunos e a Universidade de Mogi das Cruzes pela autorização da realização.

Cohen, S., Karmack, T., \& Mermelsteinm, R. (1983). A global measure of perceived stress. Journal of Health and Social Behavior, 24(4), 385-396. 